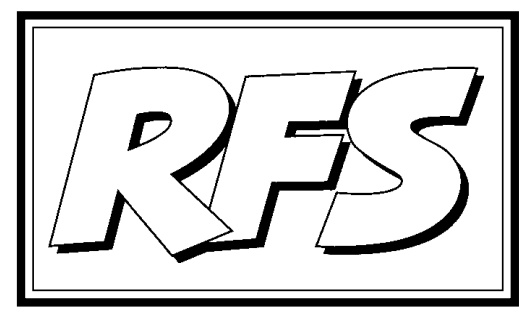

Revista de Fomento Social, 57 (2002), 43-64

\title{
Incidencia de la vida familiar sobre el contrato de trabajo
}

Teresa VELASCO PORTERO

\section{Introducción}

Desde un punto de vista aséptico e idílico, hay quien defiende que trabajo y familia son compartimentos estancos en la vida de una persona. Sin embargo, esta sería una situación más propia de máquinas que de seres humanos. Mantener que no existen relaciones entre una faceta y otra de la vida, e incluso fagocitosis de una por parte de la otra, es querer ignorar la realidad.

En una situación de libre juego del mercado de trabajo, los intereses familiares del trabajador son muy frágiles frente a sus obligaciones laborales. Por ello, la normativa laboral se tuvo que preocupar desde muy pronto de su protección. Los orígenes de este tipo de normas se remontan a 1900, fecha en que se regulan por primera vez en nuestro ordenamiento los derechos que

1 Profesora del área de Derecho del Departamento de Economía, Ciencias J urídicas y Sociología de la Facultad de Ciencias Económicas y Empresariales - ETEA adscrita a la Universidad de Córdoba. 
asisten a la obrera con ocasión del parto y nacimiento de sus hijos. Es una de nuestras primeras leyes laborales. Por supuesto que, en un momento tan temprano, la finalidad perseguida con la norma no era la conciliación de la vida familiar y laboral, sino fines mucho más primarios, como la salud de la madre y del hijo. Hoy en día, en esta materia, siguen siendo objeto de protección los mismos bienes, a los que se añaden otros. Continúa hablándose de la salud de la madre y la del hijo, y también de la familia.

Son cuestiones que están íntimamente relacionadas, siendo todas ellas muy dignas de protección. El problema es que las medidas legislativas protectoras fácilmente acaban convirtiéndose en cargas para el empresario. Si esas cargas sevinculan más a las mujeres que a los hombres, son una fuente de discriminaciones. En el proceso inciden varios factores. Por una parte, tanto el interés del recién nacido como la salud de la mujer exigen que haya determinados derechos laborales que sólo puedan ser ejercidos por la madre. Por otra, los condicionantes sociales llevan a que muchos otros derechos se ejerzan mayoritariamente por mujeres. Todo esto supone que, si la regulación legal únicamente se ocupa de establecer derechos laborales, sin acompañarlos de ningún otro tipo de medidas compensatorias para el empresario, éste va a eludir los problemas por la vía de contratar preferentemente hombres. Por todo ello, en materia de conciliación de vida laboral y familiar hay que tener muy presente la perspectiva de género.

Teniendo en cuenta todo ello, en el presente trabajo se quiere dar una visión sistemática de cómo el ordenamiento laboral protege los intereses familiares de los trabajadores, prestando especial atención a la repercusión que estos problemas tienen sobre la situación de las mujeres en el mercado de trabajo. Para ello, tras exponer las líneas generales que caracterizan el panorama laboral de la mujer en España, y su conexión con factores sociales y de asunción de cargas familiares, detallaremos los distintos derechos que tienen los trabajadores al producirse determinadas incidencias en su vida familiar. En todos los supuestos, consideramos importante reflexionar sobre cuáles son las medidas que el ordenamiento establece para compensar el efecto discriminatorio sobre las mujeres y, asimismo, cuál es la protección que tienen los trabajadores que están disfrutando de sus derechos frente a posibles despidos por parte del empresario. 


\section{Mujer, familia y trabajo}

La incorporación de la mujer al mundo laboral comenzó en España en la década de los setenta, con la modernización e industrialización del país. Las transformaciones de las condiciones materiales de trabajo derivadas del progreso tecnológico han traído consigo que se valoren más una serie de aptitudes o capacidades productivas que no son exclusivamente masculinas. La mujer se siente atraída hacia un mundo de trabajo extrafamiliar que en sí mismo se presenta gratificante, ya que permite entablar nuevas relaciones, conocer otros ambientes humanos y materiales, aumentar el consumo necesario y completar el innecesario. El aumento de la demanda de mano de obra femenina se justifica, entre otras razones por la progresiva especialización de las funciones, ya que muchas de ellas requieren cualidades más frecuentes en la mujer, o en las que la mujer se equipara al hombre.

Es a partir de 1986 cuando la tasa de actividad femenina empieza a incrementarse de forma ostensible, situándose en el tercer trimestre del año 2001 en el 40,1\% para toda España. Pese a ello, sigue estando muy alejada de la masculina $(64,4 \%$ ) con una diferencia del $24,3 \%$, siendo además la más baja de toda la Unión Europea. Entre los factores determinantes de la tasa de actividad femenina se encuentran el estado civil y el nivel de estudios. Las mujeres casadas presentan porcentajes de actividad inferiores a las solteras, mientras que en estas últimas las cifras son muy similares a las masculinas. Con respecto al nivel de estudios, a medida que éste va aumentando se incrementa la tasa de actividad de las mujeres, llegando a igualar a la masculina en las mujeres con estudios superiores. Otra variable frecuentemente asociada a la tasa de actividad es la natalidad, de manera que la disminución en el número de nacimientos que se produce en las últimas décadas en la mayoría de los países industrializados está relacionada con el ascenso continuado de la participación de la mujer en el mundo laboral.

A pesar de que la tasa de actividad femenina ha aumentado en los países de nuestro entorno en los últimos cinco años, la ocupación femenina sigue siendo prácticamente la mitad que la de los varones. Esta gran diferencia parece estar motivada porque, en buena medida, a partir de los treinta años la mujer abandona el mercado de trabajo.

La estructura del empleo femenino se caracteriza porque las mujeres siguen concentrándose en un número relativamente reducido de profesiones, con frecuencia poco cualificadas y mal remuneradas. El empleo femenino ha progresado sobre todo en el sector servicios, que ha experimentado 
una fuerte expansión en los últimos veinte años. La afluencia de mujeres ha sido particularmente importante en el sector público y parapúblico, donde las condiciones de contratación son menos desventajosas para ellas que en otros sectores. De hecho, el $70 \%$ de las asalariadas con carrera trabaja hoy en el sector público. Los créditos que se han destinado a la salud, la protección social y la enseñanza han generado un gran número de puestos de trabajo, de los que se han beneficiado un amplio colectivo de mujeres. El considerable desarrollo del empleo ligado a las transferencias sociales ha sido en todas partes principalmente femenino. También en el ámbito internacional la expansión del empleo de las mujeres se ha producido sobre to do en el sector terciario y en el público.

En España, en todos los sectores de actividad, hay menos mujeres ocupadas que hombres, aunque en el de servicios el porcentaje de mujeres está bastante próximo al de hombres; en él trabajan casi el $80 \%$ de ellas. Las mujeres ocupadas en la agricultura y la industria apenas constituyen una pequeña parte de las personas empleadas en ellos. En sectores como el de la construcción, las diferencias de ocupación entre uno y otro sexo son muy Ilamativas, ya que tan solo el $4,5 \%$ de las personas que trabajan en él son mujeres.

La vida laboral de las mujeres sigue caracterizándose por fases sucesivas de actividad e inactividad, aunque actualmente se observa una tendencia a la estabilización. Hoy, las mujeres, sobre todo las más jóvenes, permanecen activas con más frecuencia y durante más tiempo. El matrimonio ya no constituye un obstáculo para el ejercicio de una actividad laboral. De hecho, la tasa de actividad de las mujeres casadas ha aumentado más deprisa que la de las mujeres en general, si bien se trata con frecuencia de un trabajo a tiempo parcial. El número de madres que trabajan ha aumentado sensiblemente, aunque el cuidado de un hijo de corta edad sigue siendo un factor de inactividad. La situación es especialmente desfavorable para las trabajadoras de la industria que habitualmente tienen jornada completa.

En el sector servicios, en que un buen número de trabajadoras tienen jornada parcial o por cuenta propia, la maternidad dificulta menos su trabajo extradoméstico. Igual sucede con el trabajo agrícola, donde las tareas son poco delimitadas y el horario flexible, y donde, al no existir ninguna expectativa de carrera o ascenso profesional, las ausencias temporales no tienen el mismo efecto. Concretamente, en el sector agrícola, al tratarse de tareas en que no se manejan bienes de equipo y no se requiere especial entrena- 
miento, las interrupciones temporales no tienen por consecuencia la pérdida de productividad de la maquinaria, ni tampoco la pérdida de eficacia en una cadena de producción compleja con repercusiones negativas para los demás trabajadores.

Tradicionalmente la mujer abandonaba su trabajo tras el matrimonio o el nacimiento de un hijo. Sin embargo, en las últimas generaciones la proporción de abandonos de las mujeres al sobrepasar la barrera de los veinticinco años (coincidente con nupcialidad /maternidad) no sólo ha disminuido, sino que ha cambiado su signo. Los motivos para este cambio no sólo son económicos, sino también personales; principalmente la satisfacción por el trabajo sobre todo en las mujeres de mayor cualificación, entendiendo el trabajo como una fuente de estímulo mental y de contacto social.

La asunción de las responsabilidades familiares por el colectivo femenino ha generado enormes dificultades a las mujeres para compatibilizar el trabajo y la vida familiar. Por ello el legislador, a partir de 1989, intenta corregir la situación de desigualdad fáctica que afecta a las mujeres diseñando medidas de protección laboral y social dirigidas, no sólo a las trabajadoras, sino también a los hombres para posibilitar su participación en los cuidados del hijo y favorecer la contratación de mujeres en igualdad de condiciones con los hombres, la estabilidad en el empleo de las trabajadoras y su carrera profesional.

En este ámbito confluyen factores de muy diversa índole, como son los sociológicos, económicos, asistenciales, y también jurídicos, lo cual hace particularmente interesante el estudio de los efectos que sobre el contrato de trabajo de los trabajadores con responsabilidades familiares tienen las medidas de protección a la familia.

\section{Los derechos}

El ordenamiento reconoce al trabajador muy distintos tipos de derechos, según la naturaleza del acontecimiento familiar. Así, en algunas ocasiones el trabajador va a tener derecho a un permiso. La figura del permiso consiste en que el trabajador puede ausentarse del trabajo, pero manteniendo su derecho a la remuneración. En otras ocasiones, el trabajador podrá pedir reducción de jornada. En estos casos, la jornada se recorta, y de manera proporcional también se reduce la remuneración. Otras veces el ordenamiento habla del derecho a la suspensión del contrato, lo que significa que se suspenden 
temporalmente las obligaciones de trabajar y retribuir, manteniéndose la existencia del contrato. La excedencia, que es otro de los derechos que nacen para el trabajador por determinados acontecimientos familiares, tiene efectos muy parecidos.

Para exponer todos estos derechos vamos a tener en cuenta que en un primer momento histórico, el nacimiento de un hijo era prácticamente la única situación familiar que daba lugar a alguno de ellos. Con el tiempo, los supuestos protegidos se han ido ampliando, pero el nacimiento o adopción de un hijo sigue siendo una circunstancia clave, que justifica un tratamiento separado. Por ello, estudiaremos en primer lugar los derechos vinculados a esta situación, dándoles un tratamiento unitario, para desarrollar a continuación los que protegen otro tipo de situaciones.

\subsection{Derechos vinculados al nacimiento o adopción de un hijo}

El grupo de derechos más importante gira alrededor de la llegada de un nuevo miembro a la familia. Aquí el ordenamiento no solo pretende proteger a la familia, sino también la salud de la madre, si se ha producido por parto, y el interés del menor.

Para analizar las distintas incidencias contractuales a que puede dar lugar la "paternidad" vamos a distinguir dos periodos de tiempo: el embarazo y los meses próximos al parto. Dentro de cada uno de estos perio dos es importante detallar las incidencias que se producen sobre el contrato de trabajo de los progenitores y a qué responden, así como los perjuicios que la situación acarrea al empresario y cómo se intentan compensar por el ordenamiento para evitar que el derecho se convierta en una circunstancia discriminatoria para la mujer.

1. EL EMBARAZO: Durante esta fase, en la que hay una nueva vida en formación, la mujer está especialmente protegida, tanto debido a las alteraciones que se producen en su organismo, que pueden tener repercusiones en su salud, como, fundamentalmente, para garantizar la salud y seguridad del nuevo ser. Expresamente la ley reconoce los siguientes derechos de la mujer:

a) Permisos para la realización de exámenes prenatales y técnicas de preparación al parto: Este derecho se reconoció por vez primera en la Ley 31/ 1995, de Prevención de Riesgos Laborales, en los siguientes términos: “Las 
trabajadoras embarazadas tendrán derecho a ausentarse del trabajo, con derecho a remuneración, para realización de exámenes prenatales y técnicas de preparación al parto, previo aviso al empresario y justificación de la necesidad de su realización dentro de la jornada de trabajo". Hoy lo reconoce también el art. 37.3 del Estatuto de los Trabajadores, que dice lo siguiente: “EI trabajador, previo aviso y justificación, podrá ausentarse del trabajo, con derecho a remuneración, por alguno de los motivos y por el tiempo siguiente: ...f) Por el tiempo indispensable para la realización de exámenes prenatales y técnicas de preparación al parto que deban realizarse dentro de la jornada de trabajo". Es claro que los bienes jurídicos protegidos son tanto la salud de la madre como la del hijo, reconociendo la ley con este artículo la importancia de un correcto seguimiento médico del embarazo y de las modernas técnicas de preparación al parto. El coste de esta medida recae íntegro sobre el empresario, que debe soportar una disminución del tiempo de trabajo de la mujer, manteniéndole el salario.

Se trata de una medida protectora de importancia para la trabajadora, pero cuya incidencia es mínima, si se reflexiona sobre la duración de los exámenes médicos y técnicas prenatales. Como regla general, la mujer ha de someterse a una revisión ginecológica mensual, de duración equivalente a cualquier visita médica. Por tanto, una mujer que tuviera un embarazo sin complicaciones, en total asistiría a siete u ocho revisiones médicas repartidas durante un periodo de nueve meses, que podría efectuar durante la jornada de trabajo sólo si justificase que es necesario hacerlo así. En cuanto a la preparación al parto, suele realizarse durante los dos últimos meses de embarazo, a razón de hora y media dos veces en semana. También podrá ausentarse la mujer este tiempo del trabajo (en total, unas 25 horas) siempre que justifique que es necesario realizarla dentro de la jornada, ya que en ningún caso se trata de ausencias automáticas, sino condicionadas por el horario del médico o los preparadores.

b) Prohibición de fumar en cualquier área laboral donde trabajen mujeres embarazadas: (art. 70-1 b) del Decreto limitativo de venta y uso de tabaco, RD 192/1988). Aquí se protege claramente la salud del niño, y no tiene por qué suponer perjuicio para el empresario. Quizás alguna incomodidad para los compañeros de trabajo o los clientes.

c) En la misma línea, se establece la obligación del empresario de tomar medidas que eviten la exposición a riesgos que puedan afectar a la seguridad o salud de la mujer o a la del feto, o una posible repercusión sobreel embarazo 
o la lactancia de las trabajadoras. Esas medidas ha de tomarlas a través de una adaptación de las condiciones o del tiempo de trabajo de la trabajadora afectada. Cuando esa adaptación no sea posible, hay que proceder al cambio de puesto de trabajo por el tiempo necesario. Si no existiese puesto de trabajo o función compatible, la trabajadora podrá ser destinada a un puesto no correspondiente a su grupo o categoría equivalente, aunque conservando el derecho al conjunto de retribuciones de su puesto de origen (Ley de Prevención de Riesgos Laborales, art. 26). Esta obligación venía siendo recogida de forma dispersa para muy distintos trabajos ${ }^{2}$, y se extiende también al perio do de lactancia. Supone una protección de la salud de ambos sujetos, la mujer y su hijo. En el caso de quese produzca la situación de riesgo, el empresario ha de tomar las medidas oportunas, lo que en ocasiones le puede resultar costoso o complicado. Y el cambio de puesto de trabajo, incluso a trabajos de inferior categoría manteniendo la retribución, también supone una carga para el empresario.

d) Suspensión del contrato de trabajo por riesgo durante el embarazo: Este derecho a la suspensión del contrato es una creación de la Ley 39/1999, de 5 de noviembre, para promover la conciliación de la vida familiar y laboral. Viene a solucionar el problema que planteaba la aplicación del artículo 26 de la Ley de Prevención de Riesgos Laborales, en aquellos supuestos en que el empresario no tenía funciones libres de riesgo que ofrecer a la trabajadora embarazada. En estos casos, dice el nuevo art. 48 del Estatuto que el contrato de trabajo se suspenderá. La suspensión finaliza el día que se inicie la suspensión del contrato por maternidad biológica o desaparezca la imposibilidad de la trabajadora de reincorporarse a su puesto anterior o a otro compatible con su estado. A pesar de que el contrato está en suspensión, subsiste la obligación de cotizar.

La trabajadora tiene derecho a una prestación de seguridad social por "riesgo durante el embarazo", que se concede en los términos y condiciones previstos para la prestación económica de incapacidad temporal, con algunas particularidades.

2 El Convenio 136 de la OIT prohibe a las embarazadas y lactantes la realización de trabajos que entrañen exposición al benceno o productos que lo contengan; la Ley de Energía Nuclear, 25/ 1964, desarrollada en el RD 53/1992, de 24 de Enero, prohibe el trabajo en puestos con posibilidad de exposición a radiación por encima de determinadas dosis en partes determinadas de su cuerpo a mujeres gestantes o en condiciones de procrear. 


\section{LA LLEGADA DEL HIJ O:}

a) La suspensión del contrato por maternidad, adopción o acogimiento: Es el más conocido de los derechos laborales relativos a esta materia. La mujer que da a luz tiene derecho a la suspensión de su contrato de trabajo durante un periodo de dieciséis semanas, ampliables en el supuesto de parto múltiple en dos semanas más por cada hijo, a partir del segundo (art. 48-4 TRET). Suspensión del contrato significa suspensión de las obligaciones recíprocas de las partes, es decir, la mujer no realiza su trabajo pero tampoco cobra su salario. La justificación de este derecho, que está presente con distintos matices desde las primeras normas laborales ${ }^{3}$, se encuentra tanto en el esfuerzo y desgaste físico que sufre la mujer en el parto, que exige una posterior recuperación, como en las necesidades que tiene el niño de especiales cuidados y atenciones, en estos primeros momentos de su vida. Por ser doble la justificación, no vinculada exclusivamente a la recuperación física de la madre, hoy día la suspensión también puede ser ejercida también por otros sujetos, como son el padre biológico, y los padres que adoptan o acogen a un menor.

En cuanto al momento de disfrute del periodo de suspensión, señala el art. 48.4 del Estatuto de los Trabajadores que se distribuirá a opción de la interesada, respetando siempre las seis semanas inmediatamente posteriores al parto. El sentido de esta exigencia es, en parte, velar por el hijo, pero fundamentalmente preservar la salud de la madre, al entenderse que el puerperio es una etapa especialmente delicada. La ley 12/2001 ha venido a

3 El art. 9 de la Ley de 1900 preveía ya la suspensión del contrato "durante un plazo de cuatro a seis semanas posteriores al alumbramiento". En el plano internacional, el art. 3 del Convenio OIT $n$ ㅇ 3, de 1919, ya consagraba para la mujer el derecho a no trabajar durante un periodo de seis semanas anteriores al parto, y la prohibición de trabajar durante las seis semanas posteriores, recibiendo durante estos periodos unas prestaciones suficientes para su manutención y la de su hijo. Las prestaciones debían ser pagadas por el Tesoro Público o por un sistema de seguro. Este convenio fue revisado en 1952 por el Convenio núm. 103, manteniendo el derecho a suspensión por maternidad con duración de 12 semanas. La LCT de 26 de Enero de 1944 también recogía la suspensión del contrato por ausencia de la obrera, "fundada en el descanso que, con motivo de alumbramiento, señala la legislación vigente" (art. 79-3 LCT). Por su parte, el 25-4 de la LRL de 8 de Abril de 1976 establecía que "La mujer trabajadora tendrá derecho al menos a un periodo de descanso laboral de seis semanas antes del parto y ocho después del parto. El periodo posnatal será en todo caso obligatorio y a él podrá sumarse, a petición de la interesada, el tiempo no disfrutado antes del parto". El texto original del ET, de 1980 decía en su artículo 48-4 que "En el supuesto de parto, la suspensión tendrá una duración máxima de catorce semanas, distribuidas a opción de la interesada". 
completar esta regulación, ocupándose de los supuestos de nacimientos prematuros. Su disposición adicional octava añade un párrafo tercero al art. 48.4 del Estatuto, estableciendo que en los casos de parto prematuro y en aquellos en que por cualquier otra causa el neonato deba permanecer hospitalizado a continuación del parto, el periodo de suspensión podrá computarse, a instancia de la madre o, en su defecto, del padre, a partir de la fecha del alta hospitalaria. Se excluyen de dicho cómputo las primeras seis semanas posteriores al parto, de suspensión obligatoria del contrato de la madre.

a) Ejercicio del derecho a la suspensión por parte del padre biológico: Es posible en dos supuestos (art. 48-4 TRET):

- En el caso de que el padre y la madre trabajen, ésta, al iniciarse el periodo de descanso por maternidad, podrá optar porque el padre disfrute de una parte determinada e ininterrumpida del período de descanso posterior al parto, de forma simultánea o sucesiva con el de ella. La única limitación es que en el momento de hacer efectivo el disfrute por parte del padre, la incorporación al trabajo de la madre suponga riesgo para su salud. Esta salvedad no afecta más que al caso de disfrute sucesivo. Esta regulación supone una gran flexibilidad para el disfrute del permiso por parte del padre, por lo que ahora puede hablarse con propiedad de que es una suspensión "por paternidad o maternidad".

- En caso de fallecimiento de la madre, el padre puede hacer uso de la totalidad o, en su caso, de la parte que reste del período de suspensión para el cuidado del hijo. Un sector de la doctrina mantiene que este derecho puede ser ejercido por el padre con independencia de que la madre fuese o no trabajadora, ya que lo que se pretende es facilitar al hijo unos cuidados que la madre no puede prestar.

b') La suspensión por adopción o acogimiento: En lo que respecta a este derecho la ley de conciliación del año 99 introdujo importantes reformas, en un doble sentido. Por una parte mejoró algunas de sus condiciones de disfrute, asimilando en gran parte esta situación a la de nacimiento biológico, y por otra, ha fomentado el disfrute de la suspensión por parte del padre.

En los supuestos de adopción y acogimiento, tanto preadoptivo como permanente, de determinados menores, existe derecho a la suspensión de contrato de trabajo. Los menores cuyo acogimiento 0 adopción da origen al 
derecho a suspensión son los menores de seis años, y los mayores de dicha edad cuando sean discapacitados, o cuando por sus circunstancias y experiencias personales, o por provenir del extranjero, tengan especiales dificultades de inserción social y familiar.

El momento en que se inicia la suspensión puede ser el de la decisión administrativa o judicial de acogimiento 0 a partir de la resolución judicial por la que se constituye la adopción, a elección del trabajador. Con esta flexibilidad se pretende que el trabajador tenga la posibilidad de disfrutar del permiso desde el momento en que se inicia la convivencia, sin tener que esperar a la resolución judicial. La flexibilidad que pretende la norma la lleva a establecer que en los supuestos de adopción internacional, cuando sea necesario el desplazamiento previo de los padres al país de origen del adoptado, el periodo de suspensión podrá iniciarse hasta cuatro semanas antes de la resolución por la que se constituye la adopción.

La duración de la suspensión es de dieciséis semanas ininterrumpidas, ampliable en el supuesto de adopción o acogimiento múltipleen dos semanas más por cada hijo a partir del segundo.

El derecho lo pueden ejercer el padre o la madre indistintamente, aunque tan sólo trabaje uno de los dos. En el caso de que ambos trabajen, el período de suspensión se distribuirá a opción de los interesados, que podrán disfrutarlo deforma simultánea o sucesiva, siempre con períodos ininterrumpidos, y sin superar entre los dos las dieciséis semanas.

En definitiva, el nacimiento de un nuevo ser o la adopción de un niño va a tener efectos suspensivos sobre el contrato de trabajo de la madre en la mayoría de los casos pero, en su defecto, puede tenerlos sobre el del padre. A pesar de que legalmente está prevista esta posibilidad, en la práctica el derecho a la suspensión casi siempre es ejercido por la mujer. El coste de esta suspensión recae fundamentalmente sobre el Estado, pues para suplir la ausencia de remuneración salarial el sistema de Seguridad Social comprende una prestación por maternidad.

Hasta un momento relativamente reciente, el empresario soportaba el coste de las cotizaciones a la Seguridad Social por el trabajador cuyo contrato estaba en esta situación de suspensión, y los inconvenientes derivados de la necesidad de cubrir temporalmente ese puesto de trabajo con otro trabajador. Las sucesivas reformas laborales han ido en la línea de eliminar estos costes, para evitar efectos discriminatorios sobre la contrata- 
ción de mujeres. Así, actualmente se bonifica tanto la cotización a la seguridad social del trabajador sustituto como la del sustituido. En cuanto al trabajador sustituto, establece el RDecreto-Ley 11/1998, de cuatro de septiembre, en su nueva redacción dada por la ley de conciliación de 1999, que dan derecho a una bonificación del $100 \%$ en las cuotas empresariales de la Seguridad Social, incluidas las de accidentes de trabajo y enfermedades profesionales, y en las aportaciones empresariales de las cuotas de recaudación conjunta:

a) los contratos de interinidad que se celebren con personas desempleadas para sustituir a trabajadoras que tengan suspendido su trabajo por riesgo durante el embarazo

b) los contratos de interinidad que se celebren con personas desempleadas para sustituir a trabajadores y trabajadoras que tengan suspendido su contrato de trabajo durante los periodos de descanso por maternidad, adopción y acogimiento preadoptivo o permanente

La duración máxima de las bonificaciones coincidirá con la del periodo de descanso, y si no es agotado por el trabajador, los beneficios se extinguen en el momento de su incorporación a la empresa.

Por lo que respecta al trabajador que tiene su contrato en suspensión, la reciente Ley 12/2001, de 9 de julio, de medidas urgentes para la reforma del mercado de trabajo para el incremento del empleo y la mejora de su calidad, introduce una importante novedad. En su disposición adicional segunda establece que a la cotización de los trabajadores sustituidos durante los periodos de descanso por maternidad, adopción, acogimiento preadoptivo o permanente y por riesgo durante el embarazo, mediante los contratos de interinidad bonificados, celebrados con desempleados, les será de aplicación una bonificación del $100 \%$ en las cuotas empresariales de la Seguridad Social, incluidas las de accidente de trabajo y enfermedades profesionales y en las aportaciones empresariales de las cuotas de recaudación conjunta. Esta bonificación sólo es de aplicación mientras coincidan en el tiempo la suspensión de actividad por dichas causas y el contrato de interinidad del sustituto. Con esto se consigue el auténtico "coste cero" para el empresario. Tan sólo paga el salario del trabajador sustituto, pero ni su seguridad social ni la del sustituido.

b) El permiso por nacimiento de hijo: El art. 37-2 b) del ET establece que el trabajador, previo aviso y justificación, podrá ausentarse del trabajo 
con derecho a remuneración, durante dos días en los casos de nacimiento de hijo ${ }^{4}$, o cuatro si necesita hacer un desplazamiento al efecto. Obviamente, es un derecho del padre, en interés y como protección de la familia, que recae sobre el empresario, pues debe pagar el salario sin percibir contraprestación.

c) El permiso de lactancia: Se trata de un permiso ya histórico, cuyo origen se remonta a los albores del derecho del trabajo, como medida protectora tanto de la mujer como de la lactancia natural..$^{5} \mathrm{~A}$ lo largo del tiempo ha ido sufriendo cambios tanto en los fines a que se dedica, que han dejado de ser exclusivamente el amamantamiento, como en el sujeto que lo puede ejercer, que ya no es exclusivamente la mujer.

Según el art. 37-4 ET “Las trabajadoras, por lactancia de un hijo menor de nueve meses, tendrán derecho a una hora de ausencia del trabajo, que podrán dividir en dos fracciones. La mujer, por su voluntad, podrá sustituir este derecho por una reducción de su jornada en media hora con la misma finalidad. Este permiso podrá ser disfrutado indistintamente por la madre o el padre en el caso de que ambos trabajen".

En principio, la titular del derecho parece que sigue siendo la mujer, que lo podrá ejercer en todo caso, trabaje o no el padre. Sólo en el caso de que tanto el padre como la madre trabajen, podrá ser ejercido por cualquiera de los dos. Queda en situación de desprotección el padre cuya compañera ha fallecido, puesto que de la literalidad de la norma se desprende que no puede ejercer este derecho. Esta situación nos parece discriminatoria para el hijo.

El derecho admite tres modalidades de ejercicio, a elección de la persona que vaya a ejercer el permiso: ausentarse del trabajo durante una hora completa, ausentarse durante dos periodos de tiempo que sumen una hora, o bien reducir la jornada en media hora. Las dos primeras modalidades responden en mayor medida a la finalidad originaria de la institución, la

4 Tanto la LCT de 1944 (art. 67-19) como la LRL de 1976 (art.25-3) vinculaban este derecho al alumbramiento de esposa. Desde la primera redacción del ET, en 1980, se vincula al nacimiento de hijo, sea o no de la esposa.

5 El art. 9-2 de la Ley de 13 de Marzo de 1900 sobre protección de la mujer y el niño en el trabajo establecía el derecho a dos descansos retribuidos de treinta minutos, uno por la mañana y otro por la tarde, para que pudiera darse el pecho por las madres a sus hijos en periodo de lactancia. En el Derecho internacional de trabajo también se concibió este derecho, como beneficio vinculado al amamantamiento y, por tanto, exclusivo de la mujer trabajadora: art. 3.d del Convenio no 3 de la OIT. 
alimentación del niño. La última, que es la modalidad elegida de forma mayoritaria, presupone una ampliación del objeto del permiso: el tiempo se dedica no sólo a la lactancia natural o artificial del niño, sino a su cuidado y atención.

Este permiso suponeuna reducción del tiempo de trabajo, sin disminución correlativa de la retribución. La carga económica, por tanto, recae íntegramente sobre el empresario. Aunque hemos dicho quetambién el padre puede ejercer el derecho, en la práctica se trata de supuestos excepcionales, por varias razones. La primera, que el propio art. 37-4 sujeta el ejercicio paterno a que la madre también sea trabajadora y, por tanto, se lo ceda. J unto a esta importante limitación, se encuentran los condicionantes sociales y culturales, que siguen impulsando a la mujer a asumir como propios, aunque delegables en su pareja o sus padres, los trabajos relativos al cuidado de los hijos. Por tanto, para evitar que esta medida en principio protectora se convierta en discriminante, sería necesario, cuando menos, que la titularidad fuera realmente indistinta. Pero la mejor forma de conseguir que desapareciera totalmente la discriminación sería establecer una titularidad de ambos progenitores, es decir, que pudiera ejercer el derecho todo trabajador con cargas parentales, independientemente del derecho del otro progenitor ${ }^{6}$.

La potestad de concretar el derecho corresponde al trabajador, no al empresario, ya que se protege el interés del menor.

d) Permiso en caso de nacimiento de hijos prematuros u hospitalizados:

Según el art. 37.4 bis del ET, “En los casos de nacimientos de hijos prematuros o que, por cualquier causa, deban permanecer hospitalizados a continuación del parto, la madre o el padre tendrán derecho a ausentarse del trabajo durante una hora". También en este caso la concreción horaria corresponde a la persona que ejerce el derecho.

\subsection{Derechos vinculados a otras circunstancias familiares}

La llegada de un hijo no es el único acontecimiento familiar que tiene relevancia a efectos de protección laboral. Otras circunstancias dan lugar al nacimiento de distintos tipos de derechos, que tienen regulación específica.

6 En el mismo sentido, J. F. LOUSADA AROCHENA (1976), p. 13.

\section{RFS}


1. PERMISOS: El Estatuto prevé varias situaciones familiares que dan derecho a disfrutar de permisos.

a) Permiso por matrimonio: El trabajador, previo aviso y justificación, podrá ausentarse del trabajo, con derecho a remuneración, quince días naturales en caso de matrimonio. Aunque es algo común a todos los permisos, es interesante recordar que se trata de una duración mínima, que los convenios colectivos pueden mejorar, y que es un derecho independiente del tiempo que el trabajador lleve en la empresa. Como en el resto de los permisos, el derecho al disfrute nace con el acontecimiento. Esto quiere decir que el cómputo de los días comienza aquel en que se produce el evento, y no en el primer día laborable posterior.

b) Permiso por fallecimiento, accidente o enfermedad graves u hospitalización de parientes hasta segundo grado de consangüinidad o afinidad. Si con tal motivo el trabajador necesitase hacer un desplazamiento al efecto, el plazo será de cuatro días.

c) Permiso por traslado: El trabajador tiene derecho a un día de permiso por traslado de domicilio.

2. REDUCCIÓN DE J ORNADA: Otras circunstancias dan derecho del trabajador a pedir la reducción temporal de la jornada, con la correspondiente reducción del salario. Se trata de que el trabajador pueda hacer compatible su prestación de trabajo con la atención a familiares que necesitan de cuidados especiales.

La figura, que nació con la Ley de Relaciones Laborales de 1976, estaba limitada en un principio al cuidado de hijos, aunque poco a poco se ha ido ampliando la relación de sujetos cuyo cuidado da origen al ejercicio del derecho. La redacción actual del artículo 37.5 del ET dice lo siguiente: "Quien por razones de guarda legal tenga a su cuidado directo algún menor de seis años o un minusválido físico, psíquico o sensorial, que no desempeñe otra actividad retribuida, tendrá derecho a una reducción de la jornada de trabajo, con la disminución proporcional del salario entre, al menos, un tercio y un máximo de la mitad de la duración de aquella. Tendrá el mismo derecho quien precise encargarse del cuidado directo de un familiar, hasta el segundo grado de consanguinidad o afinidad, que por razones de edad, accidente 0 enfermedad no pueda valerse por sí mismo, y que no desempeñe actividad retribuida." 
En cuanto a la titularidad del derecho, hay que hacer un comentario con respecto al caso del menor o minusválido. La titularidad corresponde no sólo al padre y la madre, sino también a quien ejerza la tutela. Parece que el ejercicio puede ser simultáneo, ya que el ET eliminó la previsión que contenía la LRL de que el derecho sólo podía ser ejercido por uno de los cónyuges. Además hay que tener en cuenta que cuando el ET quiere limitar la posibilidad de ejercicio, lo hace.

Es requisito indispensable que quien solicite la reducción no desempeñe ninguna otra actividad retribuida, aunque de la literalidad del precepto parezca desprenderse que el que no debe desempeñar actividad retribuida es el menor o disminuido, o el familiar que necesita cuidados. En este sentido, era más afortunada la redacción de la LRL, que decía: “El trabajador que tenga a su cuidado directo algún menor de seis años o a un disminuido físico o psíquico, y siempre que no desempeñe otra actividad retribuida...".

La duración de la reducción será determinada por el titular del derecho, ya que el momento en que el menor cumpla los seis años de edad es tan sólo un límite máximo. Los Tribunales ya se han pronunciado sobre el importante tema de la compatibilidad de este derecho con el de reducción de jornada por lactancia, estimando que es perfectamente admisible ejercer los dos derechos al mismo tiempo 7 .

En cuanto a la concreción horaria de la reducción de jornada, y a la determinación de su periodo de disfrute dice expresamente el ET que corresponde al trabajador, dentro de su jornada ordinaria. El trabajador deberá comunicar al empresario la fecha en que se reincorporará a su jornada ordinaria con quince días de antelación. Ya hay jurisprudencia sobre este tema, que se reafirma en que la concreción horaria es una facultad del trabajador, que prima sobre los intereses de la empresa, justificándose esta primacía en el interés del menor.

El perjuicio que supone para la organización del trabajo que tenga prevista el empresario, que es el único que cabe apreciar, tiene que ser asumido por dicho empresario, sin que la ley prevea ningún tipo de compensación.

3. EXCEDENCIAS: Cuando se habla de excedencia, se quiere decir que el contrato de trabajo sigue existiendo, a pesar que durante un tiempo ni el

7 STCT de 9 de Febrero de 1980 (RA 800). 
trabajador trabaja, ni el empresario paga. La excedencia puede ser de dos tipos: voluntaria o forzosa. Aunque la nomenclatura utilizada no es muy afortunada, que sea voluntaria significa que al terminar el periodo de excedencia, el trabajador tan sólo tiene un derecho preferente al reingreso. En cambio, si es forzosa, el trabajador tiene derecho a la reserva de su puesto de trabajo, volviendo a éste al término del período solicitado.

La circunstancia familiar que primero dio lugar a la posibilidad de pedir la excedencia fue el nacimiento de un hijo. Actualmente el derecho se ha ampliado y, hoy en día, si el trabajador tiene otros familiares necesitados de cuidados, también tiene derecho a pedir una excedencia.

La evolución histórica del reconocimiento del derecho ha supuesto un significativo aumento de la protección otorgada. En un primer momento ${ }^{8}$ se limitaba al cuidado de hijos, y se refería solamente a la mujer, aunque muy pronto, con el texto del Estatuto de los Trabajadores de 1980, se reconoció el derecho a la excedencia tanto al padre como a la madre. Aunque no se calificaba la excedencia ni como forzosa ni como voluntaria, doctrina y jurisprudencia la consideraban de este último tipo, de forma que cuando se agotaba el período de excedencia, el trabajador sólo tenía un derecho preferente al reingreso en vacantes de igual o similar categoría, sin que el tiempo transcurrido computara a efectos de antigüedad.

La Ley 3/1989, de 3 de Marzo, supuso un paso adelante en la protección del trabajador que decidía hacer uso de esta posibilidad, estableciendo que el primer año de excedencia daría lugar a la reserva del puesto de trabajo y cómputo de antigüedad, manteniendo los dos años restantes como excedencia voluntaria. Con esto se avanzaba en el atractivo del ejercicio del derecho para el trabajad or, a la vez que se fomentaba en cierta medida el empleo, pues el puesto de trabajo podía ser cubierto por otro trabajador, aunque temporal.

El régimen vigente es el establecido por la ley de conciliación del año 99, que reforma el artículo $46.3 \mathrm{ET}$, flexibilizándolo y ampliando las circunstancias que dan lugar a la suspensión, que ya no es tan solo para el cuidado de hijos, sino también para el cuidado de familiares. Hay diversos aspectos del régimen jurídico de ejercicio del derecho que revisten interés.

Los titulares del derecho son los trabajadores, hombres y mujeres. No obstante, si dos o más trabajadores de la misma empresa generasen este

8 Art. 5 de Decreto de 20 de Agosto de 1970, art. 25.4 de la LRL. 
derecho por el mismo sujeto causante, el empresario podrá limitar su ejercicio simultáneo por razones justificadas de funcionamiento de la empresa.

Para hablar del beneficiario del derecho hay que distinguir. En uno de los supuestos, el beneficiario es tanto el acogido como el hijo, por naturaleza o adopción. En el otro supuesto, el beneficiario es el familiar del trabajador, hasta el segundo grado de consanguinidad o afinidad, que por razones de edad, accidente o enfermedad no puede valerse por sí mismo, y no desempeña actividad retribuida.

La duración de la excedencia también es distinta en cada uno de los supuestos. En el caso de cuidado de hijos o acogidos, la duración no será superior a tres años, a contar desde la fecha de nacimiento o, en su caso, de la resolución judicial o administrativa. En el caso de cuidado de familiares la duración no será superior a un año. En todo caso, cuando un nuevo sujeto causante diera derecho a otro periodo de excedencia, el inicio de éste dará fin al que, en su caso, se viniera disfrutando.

El objeto del derecho es que el trabajador pueda dedicarse a la atención del menor o del familiar, lo que no parece compatible con la realización de otras tareas profesionales. A pesar de ello, los Tribunales vienen admitiendo situaciones de este tipo ${ }^{9}$.

Los efectos de la excedencia son los siguientes:

- El periodo de excedencia computa a efectos de antigüedad

- Durante este tiempo, el trabajador tiene derecho a la asistencia a cursos de formación profesional, a los que debe convocarlo el empresario, especialmente con ocasión de su reincorporación. Con esto, el legislador persigue varios objetivos, siendo uno de ellos evitar una eventual extinción del contrato de trabajo por falta de adaptación a las modificaciones introducidas en el puesto de trabajo. Junto a esto, se pretende evitar que, una vez terminado el largo perio do de excedencia, haya que suspender nuevamente el contrato para que el trabajador adquiera la capacitación necesaria para realizar su trabajo ${ }^{10}$.

En todo caso, el trabajador no tiene obligación de asistir a los cursos a los

9 STSJ Valencia de 31 de Enero 1994 (A. 372).

10 R. Escudero Rodríguez y J. Mercader Uguina (1995), p. 104; S. García J iménez (2000), p. 166. 
que ha sido convocado, salvo que el curso tenga como finalidad la prevención de riesgos laborales que se deriven de las modificaciones operadas en el puesto de trabajo.

* Al término del periodo de excedencia, el trabajador tiene derecho al reingreso automático, reservándosele el mismo puesto de trabajo durante el primer año, u otro del mismo grupo profesional o categoría equivalente durante el resto.

En definitiva, cuando el trabajador hace uso de este derecho a la excedencia, para el cuidado de hijos o familiares, el empresario soporta el inconveniente de que el trabajador que venía desempeñando el puesto de trabajo lo abandona temporalmente, teniendo que contratar a un interino. El ordenamiento intenta compensar este perjuicio, ya que la disposición adicional 14a de ET establece que los contratos de interinidad que se celebren para sustituir al trabajador que esté en situación de excedencia para el cuidado de familiares, tendrán derecho a unas importantes reducciones en las cotizaciones empresariales a la Seguridad Social por contingencias comunes.

4. MOVILIDAD GEOGRÁFICA: El Estatuto de los Trabajadores contiene una referencia expresa a las circunstancias familiares, en el caso de que un trabajador sea trasladado. El art. 40.3 señala que "si por traslado uno de los cónyuges cambia de residencia, el otro, si fuera trabajador de la misma empresa, tendrá derecho al traslado a la misma localidad, si hubiere puesto de trabajo".

\section{La protección frente a despidos}

La protección del trabajador que ejerce este tipo de derechos frente a posibles represalias del empresario es un tema crucial, ya que los inconvenientes que generan estas situaciones para el empresario son una fuente de discriminaciones.

En principio, la protección era la general contra cualquier tipo de discriminación. Consiste en que, ya que la Constitución garantiza el derecho a la igualdad como un derecho fundamental, los actos del empresario que supongan discriminación son nulos y sin efecto. Esto se completaba con la doctrina del Tribunal Constitucional que establecía quelos despidos discriminatorios eran nulos con nulidad radical. De esta manera, el trabajador no tenía que 
probar que la intención del empresario era discriminar. Bastaba con aportar indicios suficientes dela discriminación, para que seprodujera una inversión de la carga de la prueba, y se trasladara al empresario la necesidad de probar que su intención no era discriminar.

La ley de conciliación de 1999 incidió en este tema, introduciendo una modificación en la regulación del despido del Estatuto de los Trabajadores. Directamente, se considera nulo el despido de los trabajadores durante el periodo de suspensión del contrato de trabajo por maternidad, riesgo durante el embarazo, adopción o acogimiento. También se considera nulo el despido de las trabajadoras embarazadas, desde la fecha de inicio del embarazo hasta la del comienzo de la suspensión del contrato, y la de los trabajadores que hayan solicitado permiso de lactancia, o para visitar a hijos prematuros. Igualmente es nulo el despido de los trabajadores que hayan pedido la reducción de jornada, o las excedencias para el cuidado de hijo 0 familiares.

El hecho de que el despido sea nulo significa que el trabajador tiene derecho a la readmisión en su puesto de trabajo, y al abono de los salarios de tramitación. Se trata de una presunción de nulidad, por el hecho de que el despido se produzca durante el período protegido, presunción que puede destruirse si se demuestra que el despido se ha basado en una causa legítima no fundada en la maternidad ni en el ejercicio de las responsabilidades familiares.

Con la nueva regulación se ha facilitado mucho la calificación de nulidad del despido, pues el trabajador o trabajadora ya no está expuesto a la libre interpretación que los tribunales hagan de los indicios de discriminación. Se ha dicho que esta protección se configura como un verdadero "blindaje" del trabajador o trabajadora que está en estas situaciones ${ }^{11}$, lo cual refleja de manera muy gráfica lo que el ordenamiento está haciendo.

\section{A modo de conclusiones}

El que hemos trazado es el cuadro general de derechos que surgen para los progenitores por el hecho de tener o adoptar a un niño. Se observa que estos derechos son de muy distinta naturaleza (suspensiones, permisos, excedencias...), y que se conceden fundamentalmente para la atención y cuidado del

11 P. Núñez-Cortés Contreras (2000), p. 178. 
menor. El legislador es consciente de que este tipo de labores son asumidas fundamentalmente por la mujer, y de que la protección de su realización puede dar lugar a discriminaciones en el acceso al empleo, por el llamado "efecto boomerang" de las medidas protectoras. Para evitar este problema, se observa una tendencia legal a ampliar la titularidad de los derechos, de forma que puedan ser ejercidos también por el padre, y a completar estos derechos con medidas de fomento del empleo.

A pesar de que se ha avanzado mucho, todavía queda un largo camino por recorrer. Es necesario que se sigan adoptando medidas en esta línea como, por ejemplo, que se autorice el ejercicio simultáneo de los derechos por ambos progenitores. También es aconsejable que sea el Estado el que asuma el coste económico que actualmente sigue soportando el empresario, como es el caso del salario correspondiente a los permisos.

Quedan también muchos flecos en la protección del trabajador, y fundamentalmente de la trabajadora, ante la extinción de su contrato por motivos de este tipo. Se ha protegido de manera expresa a estos sujetos frente a despidos disciplinarios y despidos por circunstancias objetivas, lo cual es importante. Pero sigue habiendo supuestos con respecto a los cuales la norma guarda silencio, por lo que la protección que tiene el trabajador en estos casos es la que se establece en general frente a todo tipo de discriminaciones. Nos referimos a los despidos colectivos, en los cuales no se establece de manera expresa que estos trabajadores tengan prioridad de permanencia. También son conflictivos los supuestos de contratos temporales que llegan a su término coincidiendo con la maternidad de la trabajadora, y los de embarazos que se dan a conocer durante el período de prueba. Sería deseable que la norma estableciera expresamente también en estos casos la presunción de nulidad de la extinción del contrato.

Si junto a la existencia de medidas protectoras de la estabilidad del contrato se estableciesen otras tendentes a terminar de eliminar el coste que tiene para el empresario que el trabajador ejercite estos derechos, se avanzaría en el terreno de la igualdad. Cuando al empresario tan sólo le quede asumir los trastornos en la organización del trabajo, y ésto se le compense con alguna medida adicional (como la muy acertada reducción en la cotización a Seguridad Social de los trabajadores interinos), podremos empezar a olvidarnos de los fundamentos objetivos para la discriminación de la mujer joven, cumpliendo además con los mandatos constitucionales de protección a la familia. 


\section{Bibliografía}

Alonso Olea, M. y Casas BaAmonde, MāE., (1997), Derecho del trabajo, Madrid, Civitas.

Ballester Pastor, M.A., (2000), La ley 39/99 de conciliación de la vida laboral y familiar, Valencia, Editorial Tirant lo Blanch.

Dilla Catala, Ma J., (1989), "El derecho a licencia retribuida por lactancia". Actualidad Laboral, no 17.

- (1990), "J ornadas reducidas y derecho de lactancia". Actualidad Laboral, nํ 25 .

- (1995), "La nueva regulación de la excedencia por cuidado de hijos (La Ley 4/95 de 23 de Marzo)", Actualidad Laboral, no 40, pp. 689-701.

Escudero Rodríguez, R. y Mercader Uguina, J., (1995), "Nueva regulación de la excedencia para el cuidado de hijo", Relaciones Laborales, № 11.

García I ImÉnEz, S., (2000), “El ordenamiento laboral vigente frente a los problemas familiares", Revista ICADE, no 51.

García Ninet, J .I., (1989), “Notas sobre ausencias del trabajo por lactancia (En torno al art. 37.4 del Estatuto de los trabajadores)", Revista del Trabajo, no 94, pp. 9-44.

Gorelli Hernández, J., (1997), La protección por maternidad, Valencia, Tirant lo Blanch.

- (1999), “La reciente ley 39/99 para promover la conciliación de la vida familiar y laboral de las personas trabajadoras", Relaciones Laborales, no 22.

Lousada Arochena, J.F., (1996), "El permiso de lactancia”, Relaciones Laborales, № 14, pp. 9-41.

Núñez-Cortés Contreras, P., (2000), "La configuración jurídica del despido en la Ley de Conciliación del Trabajo y la Vida Familiar", Revista ICADE, №51.

Rivas Vallejo, P., (2000), La suspensión del contrato de trabajo por nacimiento de hijos y adopción, Pamplona, Editorial Aranzadi.

Torres Díaz, I.V., (1996), "Prestación de maternidad. Derecho positivo español y perspectiva europea". Relaciones laborales, no 6, pp. 32-45. 